\title{
EWSR1/WT1 Fusion Protein
}

National Cancer Institute

\section{Source}

National Cancer Institute. EWSR1/WT1 Fusion Protein. NCI Thesaurus. Code C99214.

A fusion protein encoded by the EWSR1/WT 1 fusion gene. This protein is comprised of the transactivation domain of the RNA-binding protein EWS followed by the last 3 zinc fingers of the DNA-binding domain of Wilms tumor protein. 